\title{
LA TORTUGA Y LAS AVES: FUSIÓN Y CONFUSIÓN DE DOS FÁBULAS DE ORIGEN DIVERSO
}

\author{
Antonia María Ortiz Ballesteros \\ Universidad de Castilla-La Mancha
}

Title: The turtle and the birds: fusión and confusión of two fables of diverse origin

\begin{abstract}
Fables are a genre of long tradition that, due to their popular elements, have been adapted to different cultures and aims. In this paper we point out the double origin, classic and oriental, of the type ATU 225 , The turtle and the birds, and how was the Spanish reception in the 16 th and 17 th centuries. We also present La Fontaine's version as a point of confluence for the two traditions and the creation of a new reference model for the subsequent dissemination of this story.
\end{abstract}

Key words: Popular Literature. Fable. Exempla. Kalilah wa Dimnah. ATU225. Jataka.

\section{INTRODUCCIÓN}

Es habitual en nuestra época que cualquier relato protagonizado por animales y del que pueda extraerse alguna suerte de aprendizaje sea tipificado como una fábula y la labor de difundir y consagrar versiones, antes confiada a la tradición oral, ha quedado en manos de las tecnologías, que suelen servirse de una sola referencia (generalmente escrita) para sus nuevas propuestas. Esto crea productos con fines más didácticos y morales que estéticos, sin reparar apenas en la calidad literaria, el sentido inicial o el autor originario del texto que se transmite. Entre otras desventajas, la principal de esta nueva forma de transmisión reside en que los textos aparecen a menudo falsamente atribuidos y que el alcance de las tecnologías convierte lo espurio en autorizado. Algunas de las historias que hoy leemos con el rótulo de fábula y que se atribuyen a Esopo, a veces conservadas gracias al respaldo de una rica tradición oral, no tienen su origen en Grecia, sino en la India, y son fruto de influencias en ambos sentidos. Un número no despreciable procede de jatakas (los más antiguos se remontan al siglo $\mathrm{V}$ a. C.) y se han conservado gracias al uso que hicieron de estos relatos los monjes budistas para sus predicaciones; después, fueron vertidos por escrito en colecciones 
como el Panchatantra, cuyas versiones más antiguas datan del siglo II a. C. (Zugasti, I99r: 4I). Gracias a su traslado al pali en el siglo V, este conjunto de historias conoció amplia difusión (Andayani, 20 Io: 6r) y, en el siglo VIII, Abdalá Benalmocaffa tomó de una de estas versiones lo que consideró útil para sus propósitos, incluyéndola, bajo una nueva perspectiva, en el Calila y Dimna, traducido al castellano en el siglo XIII y con gran repercusión en la Edad Media. Los relatos recorren en consecuencia dos caminos: uno individual a partir de su difusión oral y, paralelamente, otro colectivo como parte de las colecciones en las que se incluyen por escrito, en un ciclo recurrente de lecturas, copias, impresiones e imitaciones en diverso grado.

El objetivo de este trabajo es mostrar el camino recorrido por el tipo ATU 225, La tortuga y las aves, para demostrar que los textos actuales clasificables como tal tienen orígenes diversos y provienen de la tradición esópica, la oriental o una mezcla de ambas, resultando también que la atribución explícita a Esopo, Panchatantra o La Fontaine no siempre está justificada. Para ello realizaremos un breve repaso a la recepción por escrito de cada uno de los modelos a partir de la Edad Media, distinguiendo sus rasgos característicos, con la intención última de valorar la influencia de la recepción en el hecho de que solo una de las variantes perdure hoy de manera preferente en testimonios orales (Hernández, 2005: I68); no así en los escritos.

\section{A propósito Del tipo ATU225}

La fábula que, de modo genérico, podemos identificar como La tortuga y las aves, se tipifica dentro de la clasificación Aarne-Thompson-Uther entre los números 220 a 299, dedicados a Otros animales y objetos, concretamente con el 225, La tortuga que quería volar. Atendiendo a la clasificación de Keller (1949) y después en Goldberg (1998), podemos diferenciar dos grupos: el tipo 225, de referencia, se incluiría entre J200-Jro99 (Wise and unwise conduct; J. 657: Care in selecting the creature to carry one), figurando con el J657.2: Tortoise request flight to see fields and mountains, mientras 
que la variante 225A remitiría al motivo J2357: Tortoise disregards warning and speaks, que se encuentra en otro grupo distinto (Fools and other unwise persons, J 1700-J2794), dentro de Talkative fools (J2350-J2369), si bien el elemento de imprudencia o necedad es común a ambos. Se distinguen por tanto dos líneas: en la primera de ellas, fábulas clásicas, además de la tortuga aparece un águila (ATU225) y en la segunda, fábula oriental de origen indio, la protagonista es una tortuga parlanchina o desobediente, según el caso (ATU $225 \mathrm{~A}$ ). Al primer grupo pertenecerían diversas versiones grecolatinas que parten de Esopo, entre las que se encuentran las de Fedro y Aviano, mientras que en el segundo, menos conocidas, incluimos además del Panchatantra y el Calila y Dimna las particulares historias que se recogen en Hitopadesa o provechosa enseñanza, el Océano de las historias y algunas versiones de jatakas budistas. En los siguientes apartados, bajo la premisa de existencia de estos dos grupos, señalaremos las características que permiten diferenciarlos y también aportaremos nuevos datos que clarifiquen, en la medida de lo posible, cómo se produjo la recepción del tipo La tortuga que quería volar.

2. I. La tortuga y las aves, fábula esópica: origen y evolución

Las investigaciones dedicadas a la importancia de la fábula en la Edad Media y los diferentes usos que se le han confiado desde entonces hasta la actualidad son muy numerosas (Esteban, 1994; Esteban, 1996; Monreal, 20I3; Montaner, 2013; Ortiz, 20I5) y constatan que, contra lo que cabría suponer:

la Edad Media no conoció ni a Esopo ni a Fedro de un modo directo, (las fábulas de Esopo no se vertieron al latín o los idiomas europeos hasta los años I473-1489, como se ha dicho, y Fedro lo imprimió Pierre Pithou por primera vez en I 596), sino que lo hizo a través de colecciones derivadas en verso o en prosa. Una de las más utilizadas en estos siglos fue el Romulus, un "Aesopus latinus" que sirvió de puente entre la fabulística antigua y la medieval occidental tanto en latín como en los idiomas vernáculos, que recoge versiones latinas en prosa procedentes de Fedro o de distintas fábulas griegas (Martín, 1996: 19-20). 
En este proceso, que conllevó relaciones entre lenguas y culturas, los textos fueron pasando por diversas manos y se produjeron acciones de distinto tipo, ya que, como señala C. Alvar:

Los límites entre traductor (translator en latín medieval) y autor (poeta) se van difuminando, pues, al fin y al cabo, el trabajo de ambos es muy similar en la concepción medieval. Más aún, es muy similar, también, al trabajo del glosador (glossator) y del intérprete o comentarista del texto (interpres). (Alvar, 2010: 27)

El proceso continuo de crear y recrear las obras con voluntad propia implicó también la intención de diferenciarlas con un sello característico:

En la traducción medieval la enarratio asume un poder creativo: no es simple reproducción. Puede rehacer el texto primitivo e influir de manera importante en la recepción y posterior transmisión de este texto. La forma más característica es la paráfrasis exegética que puede rehacer el texto en muchos niveles, desde el estilo a la estructura (Rubio, I997: 208).

Esto sucedió en efecto en el caso de las fábulas. Una de las primeras colecciones que lo evidencia es el Romulus, del que descienden, según se ha señalado, las 96 fábulas que el monje inglés Eudes de Ceritón (Odo Ceritonensis) escribió para fortalecer la fe cristiana entre los años I 2 I 9- I 22 I. Se vertieron al castellano, con las diferencias que cabía esperar, en diversas colecciones, entre las que destacamos el Libro de los gatos (siglo XIV), que -en la versión castellana- se inicia con el relato titulado "Lo que acaesció entre el galápago y el águila” cuyo texto es como sigue:

El galápago, seyendo en los lugares del mar fondos, rogó al águila que lo subiese al alto; ca deseaba ver los campos é las montañas; é el águila otorgó cuanto el galápago demandaba, é sobiólo muy alto, et díjole: “¿Ves agora lo que cobdiciaste ver, montes é valles?" Et dijo el galápago: "Págome que lo veo, mas querría estar en mi forado en la arcilla". Et respondió el águila: "Cumple haber visto lo que cobdiciaste." E dejólo caer en manera que fue todo quebrantado. E el galápago se entiende en algunos hommes que son pobres lazrados en este mundo, ó por aventura que han asaz segun su estado, mas non se tienen por contentos con ello, é desean sobir en lo alto, é volan en el aire, et ruegan al diablo que los suba en alto en cualquier manera; ansí 
que por derecho ó por tuerto, ó con grandes falsedades, ó por fechizos, ó por traiciones, ó por otras artes malas, algunas veces fácelos subir el diablo, é súbelos muy alto, é despues, cuando ellos entienden que su estado es muy peligroso, cobdician estar en el estado de antes donde pidieron. Estonce el diablo déjalos caer en la muerte, et despues caen en el infierno, do todos son quebrantados si se non arrepienten de antes de la muerte; ansí que suben por escalera de pecados, é caen en mal lugar mal de su grado. (Cócera, I 999).

Además del lugar preferente de apertura que el autor-traductor castellano otorga a este relato, deja su impronta en las consideraciones morales, - legando así a la posteridad la continuidad de un texto del que no se siente autor- así como su interpretación en clave cristiana, de la que sí se considera responsable: el águila se equipara al diablo por su capacidad de crear espejismos, nuevas realidades pasajeras tras las cuales vendrá el castigo terrenal o eterno, en la línea manriqueña, y ante las que es preciso estar alerta.

A partir del siglo XV, gracias a la imprenta, las colecciones de fábulas se difundieron con gran facilidad, tanto en latín como en castellano. De las primeras, destacan las de Lorenzo Valla a mediados del s. XV, que sirvieron con frecuencia a los estudiantes de Humanidades de España y que cuentan con siete impresiones en el último decenio del siglo XV (Talavera, 2007), si bien la traducción más importante de las fábulas de Esopo se basa en el texto que elaboró Heinrich Steinhöwel en Alemania y que imprimió Johannes Zeiner:

En él se encontraban el texto latino y traducción alemana, con la Vida Aesopi del humanista Rinuccio y una serie de fábulas de la tradición occidental, es decir, el denominado Rómulo y Aviano, y de la oriental, que es la versión seguida por Rinuccio.

Esta importante obra, que fue muy leída en toda Europa, se tradujo al alemán en I 473, al italiano en I479, al francés e inglés en I 484 y al español en 1489 en Zaragoza por el alemán Johan Hurus con el título de Vida del Ysopet con sus fábulas historiadas. (Martín, I 996: i7).

A lo largo del siglo XVI, las fábulas de Valla se integrarán en otras colecciones, muchas de las cuales serán traducidas al castellano, incorpo- 
rándose también las de Remicio y las de Aviano, que gozó de una enorme difusión en las escuelas medievales. Señala Talavera que:

En el Isopete encontramos veintisiete de las cuarenta y dos fábulas de Aviano. El Aesopi Phyrgis contiene, en primer lugar, cuatro fábulas de Aniano [sic] traducidas por $\mathrm{H}$. Barlandus $\mathrm{y}$, a continuación, otras treinta y ocho traducidas por G. Hermannus; la primera edición de estas fábulas se lleva a cabo en el año I 5 I3, y ya en este mismo año pasan a formar parte de las colecciones que circulan por Europa. (Talavera, 2007: 79).

En las primeras ediciones del Libro del Ysopo: famoso fablador, historiado en romançe, aparece una segunda versión del relato que nos ocupa, esta vez atribuida a Aviano:

La II. Del galápago o tortuga y de las aues

Syn gran trabajo no puede alguno subir a las cosas altas y quanto más alto sube allende de su naturaleza, tanto más grauemente cae abaxo, como esta fabula da testimonio.

Estando todas las aues ayuntadas en vno, vino el galápago entre ellas diciendo así: Si alguna de vosotras me alçasse en alto, por cierto yo le mostraría las conchas en que se crian muchas piedras preciosas, lo qual yo no puedo por mí acabar avnque continuamente anduuiesse porque yo ando muy poco de manera que según mi andar pesado en vn día entero caminaría bien poco. Las aues oyentes este offrescimiento y prometimiento engañoso, alegres muy mucho por ello, deputaronle la águila, que es la que más alto y más presto entre ellas bola, para que lo alçasse por los ayres, donde le demandaua que le mostrasse según hauía prometido las conchas criantes las piedras preciosas. E como el galápago esto no pudiesse cumplir, la águila començo de lo apretar con sus vñas ásperas. E él gemiendo dixo así: estos tormentos no huuiesse yo descido si no huuiera demandado ser alçado suso en el ayre. $\mathrm{E}$ oydas estas palabras, el águila desamparó a él y cayendo en tierra fue muerto, y despedaçado al qual natura tan fuertemente huuiere armado. Amonesta esta fabula que cada vno sea contento de su estado que la natura le dio porque la soberuia pocas vezes va o llega a buen fin, mas antes pare cayda. (Libro del Ysopo, I496: f. 7 Ir).

Durante el siglo XVI el texto se reprodujo en numerosas ocasiones. Una de las más interesantes, por compartir el mismo volumen que el Exemplario $^{\mathrm{I}}$ es La vida y fábulas del claríssimo y sabio fabulador Ysopo, nuenamente

${ }^{1}$ Esta obra se conoció en las mismas fechas que los Isopetes, pues Horus la imprimió por vez primera en $\mathrm{I} 493$ 
emendadas, de I546. El texto es idéntico al anterior y también se atribuye la fábula a Aviano (p. 97). Un cotejo nos revela las evidentes diferencias de esta versión con el Libro de los gatos, no solo en el título, sino en el protagonismo del águila, aquí compartido, ya que son las aves las que eligen al águila porque "es la que más alto y más presto entre ellas vuela". Tampoco existe coincidencia en las razones que tiene el galápago para desear elevarse, que en la versión medieval es exclusivamente la voluntad de ver mundo (un capricho, "ca deseaba ver los campos é las montañas") y ahora ha desaparecido. Una tercera diferencia se refiere al intercambio de acciones que realizan los animales; si antes el águila satisface a la tortuga a cambio de nada, dejándola caer tras cumplir el deseo ("Et respondió el águila: «Cumple haber visto lo que cobdiciaste». E dejólo caer”), en la versión de Aviano el águila cuenta con razones para elevarla (la promesa de tesoros que le hace la tortuga) y también para arrojarla al vacío (el incumplimiento de la promesa). Aún podemos añadir que el traductor/autor de la versión renacentista, a diferencia del Libro de los gatos, predispone al lector y le adelanta el final, al indicar que el ofrecimiento del galápago era "muy engañoso". Asimismo permite a la tortuga reconocer su insensatez y lo justo del castigo que le sobreviene: "Estos tormentos no hubiera yo padecido si no hubiera demandado ser alzado suso en el aire". Es cierto que la tortuga de la versión medieval también solicita al águila que la devuelva a su estado una vez satisfecho su deseo pero sin que se delimite con claridad si es por prevención de un peligro intuido o simplemente por entender que su objetivo ya está cumplido. Las referencias a las condiciones naturales de la tortuga que, por su caparazón, le hubieran permitido defenderse de otros animales y le garantizaban una larga vida, también constituyen un hecho diferencial, así como la advertencia moral, que antes se dirigía a la excesiva ambición del que desea ascender, (con alusiones medievales al demonio simbolizado por el águila) y sin embargo ahora apunta a la soberbia de quien confiando en 
su habilidad pretende conseguirlo todo (aunque sea con mentiras y a costa de otros, como en este caso).

Una tercera versión de origen clásico, también ampliamente conocida en el siglo XVI, es la de Pedro Simón, fechada en i 575 y publicada en Zaragoza como Aesopi fabvlae latine... Esta colección, que gozó de gran popularidad, especialmente en el siglo XVIII, recoge la traducción de Testudo et Aquila o, lo que es lo mismo, La tortuga y el águila, con el siguiente texto:

\section{La Tortuga i el Aguila.}

La Tortuga suplicava al Aguila, que la vezasse bolar. Pero el Aguila desaconsejavaselo diciendo, que aquello era cosa mui fuera de la naturaleza della: i la Tortuga perseveraba mucho más en la petición. Lavantándola pues el Águila asida de las uñas en lo alto, dejóla: la qual dando en unas piedras, hízose pedazos.

\section{Declaración de la Fábula.}

Esta fábula nos muestra, que los que en las contiendas no obedecieren a los consejos de los más discretos, ellos se serán [sic] causa de sus males. (Aesopi fabolae, i 575: 69).

Una vez más encontramos diferencias, tanto con la más temprana versión del Libro de los gatos como con la posterior atribuida a Aviano. En el título, vuelve a tomar protagonismo el águila, aunque ahora lo que la tortuga desea no es exclusivamente elevarse sino incluso aprender a volar. El águila se muestra sensata y se lo desaconseja (la previene) con razones lógicas: "era cosa mui fuera de la naturaleza della” pero la tortuga, lejos de escuchar el consejo, añade la testarudez a la imprudencia y persevera todavía más. Sin que sea explícita, esta enojosa insistencia lleva al águila a acceder pero también a castigar a la tortuga dejándola caer. A diferencia de la personalidad maligna del Libro de los gatos o la neutra de la versión de Aviano, aquí el águila se presenta como como modelo de prudencia.

Semejante a la anterior es la traducción versificada de Joaquín Romero de Cepeda (I 590) que, según Talavera, sigue el texto latino de Valla, 
en concreto del Incertus interpres que aparece después de Valla en el Aesopi Phrygis y donde figura con el núm. I 2 (Talavera, 2007: 90). El pacense coincide en lo básico con Pedro Simón, aunque se recrea no solo en la musicalidad de los endecasílabos sueltos sino también en la caracterización inicial y final de los personajes (el galápago es "tardo y perezoso", luego "pobre”; el águila es "Reina” y se muestra "casi enojada”), describiendo además el luctuoso desenlace con cierta complacencia: "y en un peñasco do se ha rompido/ la dura concha, y sesos, y así muere.” (f. $8 \mathrm{I}$ ). Sin embargo, la explicación que da Romero de la fábula es radicalmente diferente de la de P. Simón, pues el pacense insiste en la necedad de la tortuga por ir contra la naturaleza con símiles de carácter cómico, llenos de gracia y frescura:
Es conocida locura
digna de reprehansion
pretender nueva invención
contra el orden de natura.
quererse el feo afeytar
y el negro blanco hazerse
es engañarse, $y$ perderse
y al fin, nada aprovechar. (f. 8 Iv)

A diferencia de esta moraleja familiar, que apela a la pura sensatez cotidiana, Pedro Simón, había señalado la necesidad de seguir los consejos de los prudentes, en línea con la máxima que aparece en la tradición india, tipo $225 \mathrm{~A}$, del que nos ocupamos a continuación.

\subsection{La tortuga y las aves, fábula india: origen y evolución}

Como en el caso anterior, la variante $225 \mathrm{~A}, \mathrm{~J} 2357$, se documenta en tempranas colecciones de exempla medievales, entre las que destaca por su repercusión el Calila y Dimna. Tomamos como referencias la edición de Cacho y Lacarra (1985) a partir de uno de los dos manuscritos castellanos de finales del siglo XIII y el Exemplario, en la edición de Marta Haro (2007), impreso por vez primera en I492, traducción castellana de la obra latina de 
Juan de Capua, Directorium bumanae vitae, de la misma época, a partir de una hebrea contemporánea que tendría como fuente primera el texto árabe. Por lo demás, lamentablemente no disponemos por ahora de una traducción definitiva desde el árabe al castellano, puesto que la de Villegas (Benalmocaffa, I99I), según Döhla, se basa en la edición de Sacy de i 8 I6, realizada a partir de manuscritos bastante tardíos y sin dar a conocer exactamente sus textos originales (Döhla, 2008: 27), por lo que resulta replicable.

En el Calila, el texto pertenece a la parte El león y el buey, que corresponde al capítulo III de los XVIII que la conforman (1985: 165) y en el Exemplario al capítulo II. Del león y del buey. Y rézase del engaño y de la malicia del malsinar de los XVII (2007: I 19-I 20). Para poder acceder a la base del relato reproducimos la versión del Calila:

El que non quiere creer a su amigo, quando lo desengaña, acaesçerle ha lo que acaesçió al galápago.

Dixo el macho: $-¿$ Cómmo fue eso?

Los dos ánades y el galápago

Dixo ella: -Dizen que en una fuente avía dos ánades et un galápago, et eran amigos por la vezindat que era entre ellos. Desí vino el tiempo que les menguó el agua, et secóse la fuente. Quando esto vieron las ánades, acordaron de mudarse de aquella fuente a otra do avía mucha agua et a do serían viçiosas. Et vinieron para el galápago, et despidiéronse dél et dixierónle: Querémosnos ir deste lugar porque nos falleçió el agua.

Dixo el galápago: -A vos non falleçió el agua, que podedes ir donde quisiéredes. Mas a mí, mezquino, falleçió, que non puedo ir conbusco nin puedo guareçer sin agua. Ende vos ruego que catedes algunt consejo cómmo me podades levar conbusco.

Dixeron ellas: -Nós non lo podemos fazer, si non nos fizieses tal convenençia que, quando te leváremos et te viere alguno et fablare, que non le respondas.

Dixo él: -Así lo faré. Pues, ¿en quál guisa podría ser que me levásedes?

Dixieron ellas: -Morderás tú en medio de un fuste et travarémosnos de los cabos dél, et levarte hemos así.

Plogo desto al galápago, et leváronlo bolando por el aire; et viéronlo los omnes, et maravilláronse et dixieron: 
-Ved qué maravilla: un galápago entre dos ánades que lo lievan en el aire.

Quando el galápago esto oyó, dixo: ¡Que vos pese!

Et en abriendo la boca para fablar, cayó en tierra et murió.

Dixo el tituy a la fenbra: Entendido he lo que dexiste, mas non temas de la mar nin le ayas pavor. (Cacho y Lacarra I985: 165-166)

Un cotejo nos muestra que el autor del Exemplario es más detallista y se recrea en varias ocasiones. Ya en el inicio, la hembra tutui le señala al macho dos peligros en lugar de uno, no medir las fuerzas propias y no hacer caso de los amigos: "ni temes el peligro que tienes presente, ni quieres rescebir el consejo de tus amigos ni menos de tu mujer" (Haro, 2007: i I 9). Después, se especifica minuciosamente la razón de que las aves accedan a la petición del galápago, pues lo hacen por piedad, amistad, compasión y la soledad de la tortuga: "teniendo piedad dél, por la luenga criança, y porque no tenía forma de biuir sin el agua, ni aun quien le ayudasse para poder yr a otro lugar" (Haro, 2007: I I 9). Hemos de añadir también que en el caso del Calila, antes de aceptar llevar a la tortuga, le ponen la condición y esto confirma, por la respuesta de la interesada, la relación de plena confianza que hay entre los animales, mientras que en el Exemplario es al revés, por lo que aceptar la advertencia es más cuestión de sensatez que de confianza. Destaca también en esta colección la enumeración exhaustiva en boca de los patos de las reacciones que pueden tener las gentes: "si andando en el ayre nos ven algunos, y marauillándose de cosa tan nueua ríen, o burlan, o nos dan bozes por cosa del mundo no hables, ni respondas a nadie, y él les ofreció hazerlo así” (Haro, 2007: I i 9). Concluye esta minuciosidad del autor del Exemplario en la adjetivación que otorga a la tortuga (soberbia y necia) y que nos lleva inequívocamente a la interpretación del texto en un solo sentido, mientras que en el caso del Calila el significado es potencialmente abierto.

A pesar del intento de individualizar los textos, es evidente que la referencia de las dos últimas versiones es la misma: el Panchatantra (Cacho y Lacarra, I985: I I), obra que no fue traducida al castellano hasta i 908. El 
contenido y extensión de los cinco libros (eso es lo que significa Panchatantra) es muy desigual. Así, el Libro I, Desunión de amigos, donde se incluye el relato que nos ocupa, tiene como historia principal la del toro, los dos chacales y el león, recogiendo nada menos que XXII cuentos intercalados en una estructura de marco con sus correspondientes 425 sentencias; sin embargo el último libro se limita a XV cuentos y io6 sentencias, la mayoría de ellos protagonizados por personas y de carácter algo diferente. La Historia de la tortuga y los patos (Panchatantra, I 908: I I I- I I 3) se incluye dentro de otros y está puesto en boca de un tittibha pero no se interrumpe. Da paso al cuento XIV, Historia de los tres peces.

Las principales diferencias responden a la intención de los autores. Mientras que el tema principal para Benalmocaffa era la calidad (I99I: 25), para el compilador del Panchatantra, según figura ya en la Introducción y revelan los títulos de los primeros capítulos es la importancia de la amistad y las relaciones de confianza basadas en el respeto a los consejos. La amplitud y versatilidad de estos temas es lo que permitió que una colección, inicialmente pensada para educar a los príncipes, pudiera entenderse no solo como un tratado político, arthasāstra, sino también como un libro de conducta en general, nitisāstra, generando múltiples versiones. Los cambios que realizó Benalmocaffa afectaron tanto al texto como al orden de los relatos. Así, la Historia de los tres peces, vinculada al tema de la confianza y los consejos, aparece en el Panchatantra a continuación de la de La tortuga y las aves mientras que en el Calila lo hacía antes, separada por tres relatos que diluían los vínculos temáticos directos. Responde también a la voluntad de los intérpretes medievales la supresión que hace el Calila de las sentencias morales y la atenuación que experimenta en el Exemplario. En el Pantchatantra sin embargo tenían gran importancia:

These wise verses it is which make the real character of the Panchatantra. The stories, indeed, are charming when regarded as pure narrative; but it is the beauty, wisdom, and wit of the verses which lift the Panchatantra far 
above the level of the best story-books. It hardly needs to be added that in the present version, verse is always rendered by verse, prose by prose. (Ryder, I925: I 2).

En su traducción, Alemany no usa el verso aunque repite la máxima 3 is a modo de estribillo, al principio y al final del relato: "El que no hace caso de sus amigos que bien le quieren, perece como la estúpida tortuga que se cayó del palo" (Panchatantra, i 908: i i i). Se incorporan dos sentencias intercaladas que se vinculan al valor de la amistad y del esfuerzo, la 3 r 6: "No hay que desanimarse ni aun en tiempo calamitoso; porque con constancia se puede llegar a puerto de salvación, como el mercader que naufragado en el mar desea atravesarlo aunque sea con la nave rota". (Panchatantra, i 908: I 12 ) y la 3 17: "En bien de un amigo y en bien de la familia, hace esfuerzos el hombre sabio cuando ocurre una desgracia; así lo dijo Manú”. (Panchatantra, I 908: I I 2).

Otras diferencias se refieren a la caracterización de los protagonistas y la relación que mantienen. Mientras que en las versiones derivadas de la obra de Benalmocaffa la idea de agarrarse al palo era de las aves (son las inteligentes, por tanto), como respuesta a la petición de la tortuga (son las piadosas o sensibles), en el Panchatantra es la tortuga la que realiza la propuesta. Además, la relación de amistad entre los personajes es más profunda en el caso de la colección india, según la tristeza que la partida produce. Aún podríamos añadir otros rasgos individualizadores: el motivo que tiene la tortuga para hablar en el Exemplario es la necedad y soberbia pero en la colección india se menciona simplemente la curiosidad por saber qué es lo que los hombres dicen, sin que parezca existir un sentimiento de superioridad.

A pesar de las diferencias vistas, el relato - tal como figura en las colecciones castellanas-y su predecesor del Panchatantra son muy semejantes. La verdadera novedad se produce al comparar esta versión con su fuente, del arquetipo de las historias jataka (Andayani 2000: 6I). El hecho de que los 
monjes budistas se sirvieran de estos relatos para su predicación contribuyó a conservarlos hasta hoy con ese mismo fin y pocos cambios pero, en paralelo, se fueron popularizando gracias al uso y se incluyeron en colecciones escritas con distintos propósitos, como fue el caso del Panchatantra.

La historia que nos interesa se encuentra dentro del Canon Pali, en el último de los "tres ( $t i ́$ ) cestos (pitaka)" que constituyen el Tipitaka, un voluminoso corpus que sirve de Escrituras canónicas a la rama primitiva del budismo. Este tercer cesto está consagrado a los discursos de Buda y se divide a su vez en cinco colecciones o Nikâya-s, una de las cuales, la Khuddaka Nikâya, recoge entre sus quince títulos, el Jâtaka, compilación de 547 relatos sobre las vidas anteriores de Buda. El que nos ocupa figura con el número 2 I 5 . Los relatos están en prosa pero "se articulan en torno a unos versos que constan de una o varias estrofas gnómicas (los gâthâ), que constituyen, por decirlo así, su quintaesencia” (Inayat, 1986: ro); únicamente estos versos, en un lenguaje más arcaico, se reconocen como canónicos.

Las primeras versiones inglesas de los jatakas desde el pali, (Cowell, I895: I23-I 24; Francis, 1916: 178-179) ponen en evidencia no solo las semejanzas con las fábulas esópicas sino, incluso, su influencia directa en autores, como sugiere Jacobs (I 888: xlvii-li). En castellano, hay pocas traducciones de jatakas, si bien la popularización de La tortuga parlanchina le ha permitido estar en tres publicaciones (Inayat, 1986, Inayat, 2014, Jacobs, 2015). De forma resumida, se cuenta que en uno de sus nacimientos, Buda se reencarnó como un ministro en la corte del rey de Benarés, cuya locuacidad desmedida el joven Buda desearía corregir. Cierto día, en un estanque próximo al Himalaya sucede que vive una tortuga, que entabla amistad con dos patos salvajes (jansas), que puntualmente recaban allí para alimentarse y que, en señal de amistad, invitan al animal a su casa. La tortuga les pregunta el modo de ir, puesto que está en alto, y las aves le ofrecerán la solución con la condición de no comentarla con nadie ni abrir la boca. La tortuga acepta 
y los patos le piden sujetar con los dientes un palo que ellas agarran a su vez por los extremos. De esta forma comienzan a volar. Los muchachos de los pueblos exclaman al verlos y la tortuga intenta reprender los comentarios. Al abrir la boca pierde el palo y cae, casualmente, en el patio de la corte donde estaban el ya aludido rey locuaz y Buda. Ambos acuden al lugar advertidos por los gritos de la gente y ante la visión de la tortuga, el rey pregunta al ministro qué podría haber pasado para que de repente apareciese allí tal criatura. Buda ve la esperada oportunidad para reprender al rey y responde con su propia versión de lo narrado: "Seguramente, la tortuga y los patos eran amigos y querían que los acompañara, para lo cual se habrá colgado de un palo; entonces, cuando estaba en el aire, habrá oído algo y con el deseo de intervenir, lo ha perdido. Así pues, por no haber tenido la boca cerrada, se habrá caído, perdiendo la vida. Eso fue lo que habrá pasado". Y añade: "Esto es lo que tiene hablar en exceso y este el desgraciado final al que puede conducir", concluyendo con unos versos.

A diferencia de los casos anteriores, el relato carece de marco; la acción sucede de forma autónoma y sirve, una vez se ha producido el desenlace, para que el ministro reprenda los excesos verbales. En segundo lugar, es fundamental el cambio respecto del aprendizaje, pues el tema de la amistad y la conveniencia de hacer caso de los sabios ha dejado paso al de la locuacidad como vicio y la importancia del silencio, esencial en todas las religiones. Además, queda acentuado el carácter narrativo en detrimento del sentencioso, pues la lección solo se formula al final y no al principio. Otros elementos diferenciadores son la amistad entre los animales, que surge de la cortesía, no de la vecindad, así como el motivo que origina el viaje, como respuesta a dicha cortesía social y no como necesidad vital tras la sequía; de ahí que no exista petición ni deseo por parte de la tortuga al margen de la respuesta cortés. Debido al carácter sagrado de los patos, ellos toman la iniciativa para desplazar a la tortuga. Finalmente, la intervención de la tortuga en el 
jataka se debe al orgullo, pues no le gusta que otros hablen de ella sin que ella misma dé su versión, pero no a la vanidad.

Otras colecciones, además del Calila, también se alimentaron del Panchatantra y recogieron el relato de la tortuga y las aves, si bien han tenido poca difusión en el mundo occidental, no así en Asia. Hitopadesa o provechosa enseñanza, de Naraian Pandit, es una colección del s. XII traducida al castellano por Alemany en i 895. El análisis excedería los límites que nos hemos marcado pero no queremos dejar de apuntar algunos aspectos. El relato abre el último de los cinco libros que la componen, Sandhi o la paz y adquiere más elaboración y perfección que las versiones vistas. El marco lo constituye la historia de la tortuga y los cisnes en boca de un ministro pero después asumen la voz narrativa la tortuga, los cisnes y un pez, que nos ofrecen un total de cuatro relatos: la Historia de la tortuga y los cisnes, la de Los tres peces, la de La mujer y el amante y la de La grulla y sus crías. La del ministro (principal) organiza el resto y aborda la necesidad de hacer caso de los amigos y de las personas más inteligentes. El resto de personajes, con las distintas historias, ofrecen alternativas, considerando la conveniencia de actuar de una determinada forma antes del hecho (con una primera previsión-suposición de lo que sucederá), durante (con la improvisación) o después (con una segunda previsión basada en certezas). Los que perecen son los que no hacen caso: la tortuga y el pez inactivo. La intención principal es ejemplificar que la inteligencia consiste en actuar sin precipitarse, con seguridad y siempre siguiendo el consejo de los sabios.

El Katha sarit sagara u Océano de las historias fue escrita por Somadeva bajo los auspicios del rey Kalasa entre 1063 y ıо82, para distraer de sus pesares a Suryavati, la reina madre y también recoge la Historia de la tortuga $y$ las aves. Componen el total 350 cuentos distribuidos en is libros o lamba$k a s$, lo que supone un volumen muy superior al de otras colecciones. Este elevado número de relatos y estar escrito en verso son las principales singu- 
laridades de esta obra, de la que no hay traducción española pero sí inglesa C. H. Tawny (1 880). La Historia de la tortuga y los dos cisnes está en el Libro Io, Śaktiyaśas, protagonizado por Udayana y su hijo Naravahanadatta, cap. LX. El texto no tiene la elaboración del Hitopadesa y es muy parecido al del Panchatantra en las razones para marcharse, la advertencia de los cisnes, el mecanismo y el motivo para desprenderse... La única diferencia está al final, pues al caer son los hombres quienes matan a la tortuga.

\subsection{La tortuga y las aves: la fusión de La Fontaine}

La publicación de las fábulas de La Fontaine en i679 supuso un cambio en la andadura de los relatos vistos, que se fusionaron en uno solo. El galo conocía tanto la tradición esópica en sus diversas versiones, de largo recorrido en Francia, como la india, gracias a la traducción al francés de una versión persa del Calila I y las reelaboró de forma personal en La tortue et les deux canards, libro X, fab. 2. El singular Bernardo María de la Calzada fue el primero en traducir en 1787 la nueva versión de La Fontaine, respetando el verso (La Fontaine: 209-2 I I); siguieron Lorenzo Elízaga (La Fontaine: 434-436) y Teodoro Llorente y Olivares en I 883 y i 885 respectivamente (La Fontaine: 1 92). Esta última traducción, en prosa, está en la base de muchas adaptaciones y ediciones posteriores si bien, cuando se trata de antologías o selecciones, raramente incluyen el relato que nos ocupa. Pese a que esta fábula no tuvo la fortuna de otras, como La lechera o La cigarra y la hormiga, La Fontaine tuvo el mérito de seleccionar elementos de las dos tradiciones, fusionándolos y otorgándoles un nuevo sentido que bajo su indiscutible autoridad en el género fabulístico ha conseguido mantener la historia viva hasta hoy.

Son tres los elementos esenciales que recoge de las versiones esópicas: el deseo de viajar de la tortuga para ver mundo, los defectos de la vanidad y las consecuencias de la curiosidad sin fundamento. De la tradición india mantiene el protagonismo de dos patos en lugar de un águila, el mecanis- 
mo que sirve para desplazar a la tortuga (un palo o bastón sujeto por los tres animales) y también la presencia de gente, así como la reacción a los comentarios de estos como causa para la caída de la tortuga. A todo lo anterior, La Fontaine añade elementos propios, como la caracterización de la tortuga desde el inicio como alguien con "mala cabeza”, la falta de vínculos (de amistad o vecindad) entre los animales, una expansión que enfatiza los atractivos de conocer mundo, las alusiones clásicas a Ulises como alarde de erudición y una amplia enumeración en la moraleja de los defectos de la tortuga, que posteriormente los traductores acomodan según sus gustos, según puede verse en la comparativa:

\begin{tabular}{|c|c|c|}
\hline \multicolumn{3}{|c|}{ La Fontaine } \\
\hline \multicolumn{3}{|c|}{$\begin{array}{c}\text { Imprudence, babil, et sotte vanité, } \\
\text { Et vaine curiosité, } \\
\text { Ont ensemble étroit parentage. } \\
\text { Ce sont enfants tous dún lignage. }\end{array}$} \\
\hline B. M. de la Calzada & L. de Elízaga & T. Llorente \\
\hline $\begin{array}{l}\text { La charlatanería, la imprudencia, } \\
\text { la necia vanidad, la suficiencia, } \\
\text { y todas las empresas, que son vanas, } \\
\text { por lo común van juntas como hermanas }\end{array}$ & $\begin{array}{l}\text { La curiosidad ociosa, } \\
\text { la vanidad, la imprudencia. } \\
\text { Son de la misma familia } \\
\text { y muy cercanas parientas }\end{array}$ & $\begin{array}{l}\text { Imprudencia, charla, tonta vanidad } \\
\text { y vana curiosidad son primas hermanas: } \\
\text { todas proceden del mismo tronco. }\end{array}$ \\
\hline
\end{tabular}

A diferencia de otras fábulas, en esta ocasión, nuestro fabulista por antonomasia, Samaniego, decidió seguir su propio criterio al versionar la historia, en la que no sigue a La Fontaine. Su poema La tortuga y el águila, número XI del libro IV, toma solo rasgos de la tradición esópica en la segunda versión señalada, respetando la moraleja de Pedro Simón: "Para que así escarmiente/ quien desprecia el consejo del prudente” (Samaniego, I 78 I: I 25 ). Esta respetuosa versión no tuvo mucha repercusión mientras que la de La Fontaine experimentó nuevas transformaciones, adaptaciones y cambios.

\section{A MOdo DE CIERRRE}

El tipo ATU225 y su variante 225A responden a dos líneas diferentes en su origen y evolución, con recepción desigual, lo que ratifica la afirmación de Adrados de que para estudiar los géneros populares no basta con ofrecer textos y vincularlos a tipos, sino que hay que analizar caso por caso 
e "insistir que estas fábulas tienen orígenes concretos y vías y fechas concretas de difusión" (Rodríguez Adrados, 1991: 79). En lo que se refiere a La tortuga y las aves, presenta dos tipos que estaban claramente diferenciados inicialmente en cuanto a personajes, argumento y moraleja. Mientras que el tipo ATU225 de tradición clásica, conocido a través de Aviano particularmente, se sirvió de una pareja de animales antagonistas (águila y tortuga), en el segundo existía amistad entre dos aves y una tortuga por razones de convivencia. Las razones para el vuelo eran también distintas, contraponiéndose el capricho del primer tipo a la necesidad vital de la variante india. Diferían, así mismo, en la moraleja, motivada siempre por la característica de la tortuga (sea ambición o necedad).

Sea por la aplicación moral de la fábula o por otras razones, el destino de los relatos vinculados a un tipo y su variante también ha resultado desigual. Los relatos de corte clásico fueron ampliamente difundidos y versionados tanto oralmente como por escrito en territorio hispánico, mientras que el de raíces budistas se documenta de forma anecdótica. Su popularización en nuestra lengua se debe a las traducciones de la versión francesa de La Fontaine, quien, en lugar de ceñirse a una sola tradición como hizo Samaniego, decidió fusionar con innegable maestría elementos de ambas líneas. A partir del siglo XIX hay otras muestras de la confusión de las variantes y se ofrecen como del griego indistintamente las versiones de La Fontaine o de Esopo (Miér, I97 I: 35 y 178-179). Hoy, la referencia preferente para la transmisión de este tipo parece ser el texto de La Fontaine, que se difunde en la red con diversas modificaciones, contaminado también con la línea clásica, de mayor alcance por ahora. Sigue siendo puntual la recepción del tipo $225 \mathrm{~A}$, del que solo encontramos algunas muestras en adaptaciones del Calila para niños a partir de avanzado el siglo XX (Jané, I 993; Bravo-Villasante, I990; Caso, 2012; Martínez, 2015; Merino, 2016) y en actualizaciones de jatakas budistas (Brahm, 2015). 


\section{BIBLIOGRAFÍA}

Aesopi fabvlae latine atq. Hispane scriptae quaq. Fieri protuit diligentia fidelitateq. E Graeca lingua induas has traductae... interprete Petro Simone Aprileo. Zaragoza: Michaelis Huessa, I 575.

Alvar, C. (2010), Traducciones y traductores. Materiales para una historia de la traducción en Castilla durante la Edad Media, Alcalá de Henares: Centro de Estudios Cervantinos-UAH.

Andayani, A. (2010), "Story motif variety in Pancatantra indian fable", Parafrase (Io), o2, pp. 6 I-7 I.

Benalmocaffa, Abdalá (r99i), Calila y Dimna, trad. de Marcelino Villegas, Madrid: Alianza Editorial.

Bra hi, A. (20 I 5). La vaca que lloraba y otros cuentos budistas acerca de la felicidad. Barcelona: Kairós.

Bravo-Villasante, C. (sel.) (1990), Calila y Dimna, Palma de Mallorca: José J. de Olañeta, Biblioteca de Cuentos maravillosos 55.Cacho, J. M. y Lacarra, M. J. (eds.) (I985), Calila e Dimna, Madrid: Castalia.

Caso, $\mathrm{M}^{\mathrm{a}}$ T. (adap.) (20 2), Cuentos y fábulas para niños. Calila y Dimna. Barcelona: Nobel.

Cócera, D. (ed.). (1999), "Libro de los gatos", Revista Lemir n ${ }^{\circ}$ 3. Disponible en http://parnaseo. uv.es/Lemir/Textos/Gatos/gatos.html . [Consultado el I $_{8} / \mathrm{IO}_{\mathrm{O}}$ 2017]

Cowell, E. B. (ed.) (I 895), The jätaka or stories of the Buddha's former births, Vol. II, trans. By W. H. D. Rouse, Cambridge: University Press. Disponible en https://archive.org/stream/ jatakaorstoriesoozcowe\#page/ I 22/mode/ 2 up . [Consultado el i $8 /$ Io/2017]

Döнla, H. J. (2008), El libro de Calila e Dimna (I25I): edición nueva de los dos manuscritos castellanos, con una introducción intercultural y un análisis lexicográfico árabe-español, Zürich: University.

Esteban, L. (1994), "Las fábulas esópicas, texto escolar en la alta y baja edad media”, Helmantica, XLV, pp. 485-509.

Esteban, L. (1996), Coret y Peris (1683-1760) o el humanismo filológico y docente, Valencia: Universidad de Valencia.

Francis, H. T. (ed.) (1916), Jātaka tales, Cambridge: University Press. Goldbert, H. (1998), MotifIndex of medieval spanish folk narratives. Tempe, Arizona: Medieval Renaissance text studies.

Haro, M. (ed.) (2007), Exemplario contra los engaños y peligros del mundo, Valencia: Universidad.

HERNÁNDEZ, Á. (2005), "Literatura y tradición oral. Fábulas y cuentos folclóricos de animales (I)", Revista de Folklore, 299, I 5 8-176.

Inayat Khan, Nur (1986), Veinte cuentos jataka, trad. Jordi Quingles, Palma de Mallorca, José J. de Olañeta Ed., Biblioteca de Cuentos maravillosos n ${ }^{\circ}$ i 4.

Inayat Khan, Nur (2014), Veinte historias jataka, trad. Puran Füchsling, Zürich: Proyecto Petama.

JACOBS, J. (1 888), The earliest English version of the fables of Bidpai, London: David Nutt.

JACOBS, J. (1894), The Fables of Aesop London: Macmillan and Co., pp. I I I-I I 2.

JACOBS, J. (20 I 5), Fábulas y leyendas de la India, trad. Eva González Rosales, Barcelona: Quaterni. (Ed. original, Indian fairy tales, I 892).

Jané, A. (1992), Fábulas de animales. Il. Juan Ramón Alonso. Zaragoza: Edelvives, Col. Ala Delta I06. ( ${ }^{\mathrm{a}}$ ed.; $\mathrm{I}^{\mathrm{a}}$ : 1990).

Keller, John Esten (1 949), Motif-Index of Medieval Spanish Exempla, Knoxville: Univ. of Tenessee Press.

La Fontaine, Jean de (i 883), Fábulas, trad. de Lorenzo de Elízaga, París/México: Ch. Bouret

La Fontaine, Jean de (i 940), Fábulas, trad. de Teodoro Llorente, Barcelona: Montaner y Simón.

La Fontaine, Juan de (1787), Fábulas, trad. de Bernardo María de la Calzada, tomo II, Madrid: Imprenta Real.

La vida y fábulas del claríssimo y sabio fabulador Ysopo, nuenamente emendadas. Exemplario en el qual se contienen muy buenas doctrinas, debaxo de graciosas fábulas ( I 546), Amberes: Iuan Stelsio.

Libro del Ysopo: famoso fablador, historiado en romançe (1496), Burgos: Fadrique Alemán de Basilea (disponible en http://gallica.bnf.fr/ark:/ I 2 I 48/bpt6k854I7I I/f Io.image.r=ysopo) . [Consultado el is/10/2017]. 
Martín, Fco. (1996), Antología de fábulas esópicas en los autores castellanos, Cuenca: UCLM.

Martínez, R. (adap.) (201 5), Del maravilloso mundo de Calila y Dimna. Barcelona: Thule.

Merino, J. Ma (ed.) (2016), Calila y Dimna, Madrid: Páginas de Espuma.

MiÉr, E. de (trad.) (I 87 I), Las fábulas de Esopo, traducidas directamente del griego, y de las versiones latinas de Fedro, Aviano, Aulo Gellio, etc..., Madrid: José Astort y Co.

Monreal, J. L. (2013), "El uso didáctico de la fábula en la literatura renacentista alemana”, Estudios bumanísticos, Filología, 35, pp. 5 1-62.

Montaner, A. (2013), "Análisis del tratamiento de la fábula desde una perspectiva intercultural. Esopo y la tradición española en las aulas de sexto curso de Educación Primaria”, Ensayos, 28. Disponible en: http://www.revista.uclm.es/index.php/ensayos . [Consultado el $18 / 10 / 2017]$

Ortiz, A. M. (2015), "Actualización didáctica de las fábulas: la integración de aprendizajes lingüísticos y literarios desde una perspectiva pragmática”, Lectura y signo: revista de literatura, (Io), I, pp. I 27-I 39.

Panchatantra o cinco series de cuentos (1908), trad. José Alemany y Boluffer, Madrid: Sucesores de Hernando.

Rodríguez Adrados, F. (I99i), “Fábulas y cuentos en los Balcanes”, Sociedad española de estudios clásicos, pp. 63-80. Disponible en | http://interclassica.um.es/investigacion/hemeroteca/ e/estudios_clasicos/numero_ioo_rig9//fabula_y_cuento_popular_de_tradicion_antigua_ en los balcanes. [Consultado el $18 / 10 / 2017]$

Romero dE CÉPEDA, J. ( 1590$)$, Vida y exemplares fábolas del ingeniosissimo fabulador Esopo Frigio... Sevilla: Juan de León.

Romero, A. y Romero, L. (2002), "Lectura y literatura didáctica moral: una lectura comparada de tres fábulas mitológicas de Félix María de Samaniego y sus implicaciones didácticas", Lenguaje y textos, i 8, pp. IоI-I I 5 .

Rubio, J. (I 997), “Algunas características de las traducciones medievales”, Revista de Literatura Medieval IX, pp. 197-243.

Ryder, A. W. (I 925 ), The Panchatantra of Vishnu Sharma, University of Chicago Press: Chicago.

Samaniego, F. Ma . (I78I), Fábulas en verso castellano..., Valencia: Benito Monfort. Disponible en http://www.cervantesvirtual.com/obra-visor/fabulas-en-verso-castellano-para-uso-del-realseminario-vascongado -o/html/ff I 8576c-82 b I-I I df-acc7-002 I 85ce6o643.html\#I_74.(Consultadoel18/10/2017)

TAlavera, S. (2007), La fábula esópica en España en el siglo XVIII, Cuenca: UCLM.

Tawny, C. H. (trad.) (1 880), The Kathá Sarit Ságara or Ocean of the Streams of Story, Calcuta: J. W. Thomas.

Zugasti, M. (1990), "Las fábulas del Panchatantra y sus nuevas versiones en el Kalilah wa Dimnah árabe y el Calila e Dimna español”, Papeles de la India, XIX (3), pp. 40-6I.

recibido: noviembre de 2017

aceptado: febrero de 2018 
